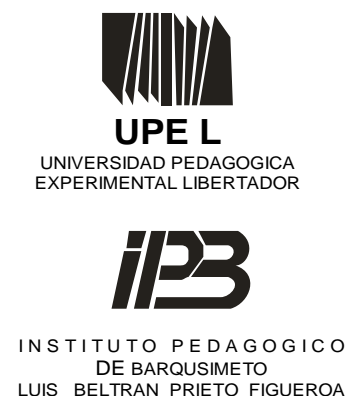

LUIS BELTRAN PRIETO FIGUEROA

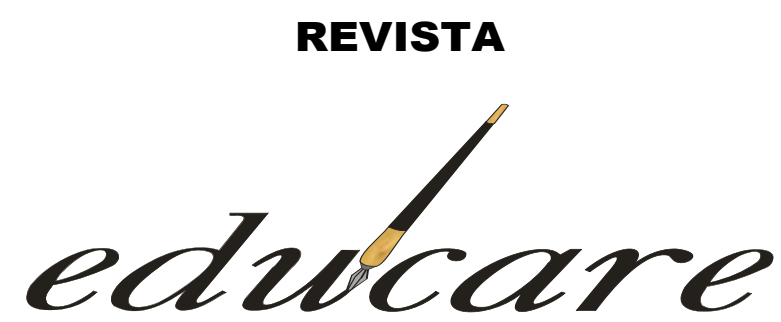

Órgano Divulgativo de la Subdirección de Investigación y Postgrado del Instituto Pedagógico de Barquisimeto “Luis Beltrán Prieto

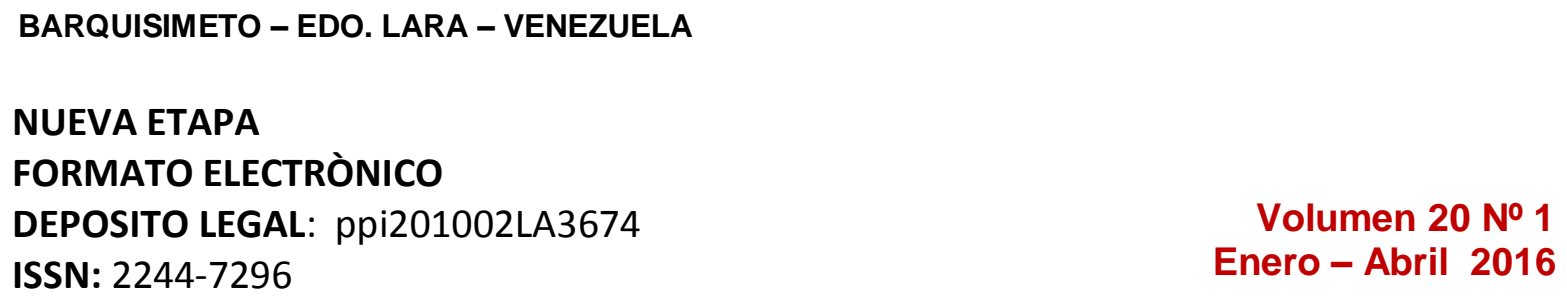

NUEVA ETAPA

FORMATO ELECTRÒNICO

DEPOSITO LEGAL: ppi201002LA3674

\title{
LA ESCRITURA EN LOS ENTORNOS DIGITALES
}

WRITING IN DIGITAL ENVIRONMENTS

\author{
Mario Boza *
}

\section{* UNIVERSIDAD PEDAGÓGICA EXPERIMENTAL LIBERTADOR. INSTITUTO PEDAGÓGICO DE BARQUISIMETO UPEL-IPB}




\section{LA ESCRITURA EN LOS ENTORNOS DIGITALES}

WRITING IN DIGITAL ENVIRONMENTS

REVISIÓN DOCUMENTAL

Recibido:20-01-2016
Mario Boza *

UPEL IPB

Aceptado:30-03-16

\section{RESUMEN}

El presente artículo enmarcado en una revisión documental tiene como propósito generar un cuerpo de reflexiones teóricas acerca de la escritura en los entornos digitales; su importancia, sus características, sus modos de producción y diseminación mediante la utilización de las tecnologías de la información y comunicación (TIC). Para realizar el presente trabajo se obtuvo la información a través de los principales exponentes y especialistas en el tema objeto de estudio. En este sentido, se utilizaron diversos textos impresos y electrónicos, que permitieron organizar de forma analítica y crítica la información recogida en varias fuentes. Se concluye que las TIC han modificado todo a la vez; los soportes de la escritura, la técnica de su reproducción y diseminación, y las maneras de leer.

Descriptores: TIC, escritura digital, entornos digitales

\begin{abstract}
This article, framed in a documentary review, aims to generate a body of theoretical reflections about writing in digital environments; Its importance, its characteristics, its modes of production and dissemination through the use of information and communication technologies (ICT). To perform the present work, the information was obtained through the main exponents and specialists in the subject of study. In this sense, several printed and electronic texts were used, which allowed analytical and critical information to be collected from different sources. It is concluded that ICT has changed all at once; writing supports, the technique of its reproduction and dissemination, and the ways of reading.
\end{abstract}

Keywords: ICT, digital writing, digital environments

\section{INTRODUCCIÓN}

\footnotetext{
* Profesor de Inglés. Magíster en Administración Educacional. Doctor en Educación egresado de la VII cohorte del Programa Interinstitucional de Doctorado en Educación (PIDE). Experto en Procesos E-learning (FATLA). Miembro de la Asociación Mundial de Tutores en Línea. Experto en Medios Digitales (FATLA). mario_boza@hotmail.com.
} 
El ser humano se caracteriza por su naturaleza social, por la necesidad de relacionarse con sus congéneres a través de las diferentes formas de comunicación. Por ello, sin importar el grado de desarrollo científico y tecnológico de una sociedad, el lenguaje humano, tanto oral como escrito, adquiere cada día mayor valor como sistema de comunicación y de representación del mundo.

El medio oral tiene lugar en un contexto de situación; es decir, en un conjunto de circunstancias de carácter social, emocional y cultural que determinan el acto lingüístico, razón por la cual no es necesario ser demasiado explícito, puesto que muchas de las referencias están fuera del discurso oral, cosa que no sucede con el escrito. Éste carece de un contexto situacional, por lo tanto hay que crearlo lingüísticamente. Por eso resulta más difícil comunicarse por escrito (Díaz, 1999).

Con el auge cada vez más vertiginoso de las tecnologías de la información y la comunicación (TIC), las fronteras entre el discurso oral y el escrito parecen difuminarse gracias a la hipertextualidad de la escritura digital. Ésta rompe con la linealidad del texto analógico y le permite al escritor utilizar enlaces, vínculos o llamadas (links), lo cual le facilita al lector la libertad de saltar adelante y atrás en el texto sin la necesidad de ceñirse obligatoriamente al hilo discursivo.

En atención a lo mencionado anteriormente, asegura Cassany (2004), todas las actividades humanas basadas en la escritura están emigrando a lo digital, a lo telemático y a las pantallas, y una parte muy importante de la comunicación escrita, tradicionalmente desarrollada en entornos analógicos con papel, libro, lápiz, correo postal, hoy está cambiando de modo acelerado hacia entornos digitales.

Como consecuencia de lo señalado, se ha abierto un debate en torno a la nueva forma de escribir en Internet. Muchos piensan que hay una pérdida en la calidad del lenguaje, que los estudiantes acusan una menor capacidad de redacción y otros culpan a la Web de acabar con la ortografía. Algunos, por el contrario, no creen que las tecnologías vayan a producir una hecatombe y argumentan que el uso de la lengua va ligado al intelecto de los seres humanos, y porque haya nuevas prácticas no va a acabar. Para éstos, si hay un problema no es de la Red, sino de la educación. Quien tiene que enseñar ortografía no es Google, es la escuela, aseguran. Lo cierto es que Internet no es más que una tecnología en la que la 
escritura cambia como lo ha hecho a lo largo de la historia: piedra, papiro, imprenta y, ahora, bits.

En atención a lo planteado hasta ahora, surge el presente artículo enmarcado en una revisión documental, que tiene como propósito generar un cuerpo de reflexiones teóricas acerca de la escritura en los entornos digitales; su importancia, sus características, sus modos de producción y diseminación mediante la utilización de las tecnologías de la información y la comunicación (TIC).

A partir del planteamiento anterior, en esta revisión documental se abordarán los siguientes aspectos: características de la escritura en entornos digitales (ED), la escritura en una revista electrónica, la escritura en un medio digital, la escritura en las Redes Sociales y como colofón, se presentan las consideraciones finales que representan un cuerpo de reflexiones relacionadas con la importancia sustantiva de la alfabetización digital de docentes y estudiantes.

Es de hacer notar que para realizar el presente trabajo la información fue obtenida a través de los principales exponentes y especialistas en el tema objeto de estudio. En este sentido, se utilizaron diversos textos, tanto impresos como electrónicos, que permitieron organizar de forma analítica y crítica la información recogida en diversas fuentes.

\section{CARACTERÍSTICAS DE LA ESCRITURA EN ENTORNOS DIGITALES (ED)}

Varios autores coinciden en establecer una serie de particularidades específicas en la escritura digital. Este es el caso de Cassany (2000), quien afirma que una de las principales características de la escritura digital es que rompe con la linealidad del texto analógico (se lee desde el inicio, pues tiene un orden predeterminado), para pasar a conformar el hipertexto como estructura básica, es decir,

...el escrito lineal y unidireccional se rompe en diversidad de fragmentos autónomos que se conectan entre sí con enlaces (links) o llamadas que permiten saltar ágilmente de uno a otro, en cualquier dirección -como una araña que se desplaza a través de una telaraña o de una red (p. 4).

Agrega el autor antes citado, que en conjunto, con la estructura híper e intertextual el escrito se convierte en un objeto comunicativo más abierto (que admite actualizaciones continuadas), versátil (permite diversidad de itinerarios), interconectado (relacionado con el 
resto de recursos enciclopédicos de la red) y significativo (multiplica sus posibilidades interpretativas).

Por su parte, Díaz (2000) señala que todo producto diseñado para Internet debe ser multimedia (compuesto por información, imagen, sonido y texto), hipermedia (que le permita al usuario navegar en el contenido según su voluntad) e interactivo (que le permita al usuario preguntar y obtener respuestas).

En el mismo orden de ideas, Day (2005), señala que al escribir un trabajo científico para la Web no se utilizan ya páginas en el sentido tradicional. El artículo puede ser una sola página consistente en una larga ventana en la que se puede avanzar o retroceder (scroll), o puede dividirse en breves segmentos, que corresponden a "páginas" y tienen cada uno un enlace URL distinto. Vale la pena explicar que URL es Uniform Resource Locator por sus siglas en inglés y significa Localizador Uniforme de Recursos, el cual le permite al navegador encontrar una dirección o sitio en Internet.

Para Chartier (2010), la textualidad electrónica permite desarrollar las argumentaciones o demostraciones según una lógica que ya no es necesariamente lineal ni deductiva, tal como lo implica la inscripción de un texto sobre una página, sino que puede ser abierta, expandida y relacional gracias a la multiplicación de los vínculos hipertextuales. Como consecuencia, agrega el autor citado, "el lector puede comprobar la validez de cualquier demostración consultando por sí mismo los textos (pero también las imágenes, las palabras grabadas o composiciones musicales) que son el objeto del análisis si, por supuesto, están accesibles de forma digitalizada" (p. 37).

Las características mencionadas, reflejan de manera categórica como "Un nuevo orden escrito emerge al ritmo que se impone lo digital" (Cassany, ob. cit., p. 8). No obstante, la escritura conserva su esencia originaria: la socialización de las actividades humanas y la difusión del conocimiento, en un continuo intercambio de sentidos y significados sobre las bases del interaccionismo simbólico. En este enfoque la unidad de estudio no es el individuo (características personales y comportamiento individual), ni tampoco el grupo (estructura social), sino la interacción entre ambos. (Bisquerra, 1989).

En relación con lo señalado, Buendía, Colás y Bravo (1998), afirman que:

La interacción es un punto crucial entre los individuos y el grupo social. Por tanto, el interaccionismo simbólico se interesa por comprender cómo los individuos aprenden los significados en instancias concretas de interacción, es 
decir, los procesos por los que se elaboran los símbolos y a su vez éstos son utilizados para guiar nuevas acciones (p. 242).

En esa interacción entre los individuos el conocimiento no se transmite de una persona a otra sino que se construye socialmente, mediado por las experiencias de aprendizaje y de la cultura de una generación adulta a otra en proceso de formación (Principios de la construcción social del aprendizaje). En consecuencia, "el aprendizaje es el resultado de la elaboración conjunta de significados acerca del objeto de estudio mediante las interacciones y transacciones que se producen entre el docente y sus estudiantes y entre los mismos estudiantes" (Dávila, Ruiz y Francisco, 2013, p. 128).

Cabe señalar que entre las vías para la socialización del conocimiento y la interacción social, en este caso a través de un canal o medio digital, se puede mencionar las revistas electrónicas alojadas en los diferentes repositorios institucionales de muchas universidades nacionales e internacionales, los periódicos digitales, redes sociales como Facebook, twitter, los blogs, scribd, slideshare y el correo electrónico.

Por razones de espacio, a continuación se abordarán solamente las revistas digitales o electrónicas, los periódicos digitales y las redes sociales Facebook y Twitter. Estos recursos de la Web han pasado a formar parte de la cotidianeidad de las personas en un mundo altamente globalizado.

\section{LA ESCRITURA EN UNA REVISTA ELECTRÓNICA}

Una de las principales características de la escritura electrónica o digital es que rompe con la linealidad del texto analógico, es decir, el escrito se convierte en un objeto comunicativo más abierto, tal como lo señala Cassany (ob. cit.). Sin embargo, al momento de elaborar un texto escrito se debe tener en cuenta su propósito y la audiencia a quien va dirigido, ya que no es igual escribir en un chat que hacerlo para una revista electrónica. Son dos contextos completamente diferentes; los chats imponen una novedosa forma de escritura, sin hablar de la sintaxis y del vocabulario, mientras que en las revistas digitales los escritos requieren una planificación reflexiva y la puesta en marcha de múltiples mecanismos para lograr transmitir conocimiento claro y atractivo para el lector, ya sea en un informe, un trabajo académico o un manual de instrucciones, por ejemplo. 
En relación con las revistas electrónicas, Day (ob. cit.), afirma que son un nuevo fenómeno y se asemejan a la que se distribuyen impresas en donde los artículos han sido revisados por expertos y redactores antes de su publicación. La revisión generalmente es realizada por el consejo editorial, quien a su vez lo remite a dos expertos en la materia para que evalúen y revisen el manuscrito. Esta tiene como propósito muy bien definido el logro de los criterios de calidad que distinguen a las revistas científicas, pues al no ser sometido al arbitraje por parte de expertos, cualquier artículo carecerá de verdadera credibilidad.

Una de las principales ventajas de estos recursos digitales, según el autor antes citado, es que los números de las revistas se publican en menos tiempo que el que se necesita para los impresos, porque las publicaciones en papel tienen todavía que compaginarse, imprimirse y embalarse para el correo antes de ser distribuidas. En cambio la distribución en la Web es instantánea en cuanto la revista electrónica se publica.

En este punto es pertinente aclarar que al escribir un artículo para algún sitio Web, en este caso revistas en línea, se deben tomar ciertas medidas que aseguren que el documento será consultado por el usuario interesado. En tal sentido, es de obligatorio cumplimiento acompañar el resumen con las palabras clave que permitirán su ubicación por los diferentes motores de búsqueda, ya que de lo contrario, la publicación se perderá en ese inmenso océano de información que es Internet. Aunado a esto, el autor debe incluir su dirección electrónica y una breve descripción de su currículo, como información corroborante.

A continuación se presenta una serie de pautas establecidas por la Revista EDUCARE, que es un órgano de divulgación científica, de edición periódica publicada por la Subdirección de Investigación y Postgrado del Instituto Pedagógico "Luis Beltrán Prieto Figueroa" de Barquisimeto, cuyos objetivos son:

1. Servir como órgano divulgativo de teorías y prácticas pedagógicas innovadoras, ensayadas dentro de la institución o fuera de ella, que contribuya al mejoramiento de la calidad educativa.

2. Dar a conocer los resultados de producciones investigativas generadas en los diferentes departamentos y unidades de investigación de la UPEL y otras instituciones académicas nacionales e internacionales.

3. Estimular la producción investigativa de la UPEL y de otras universidades en los distintos niveles de educación. 
La Revista EDUCARE es una publicación arbitrada mediante el método doble ciego, ya que todos los artículos son objeto de una evaluación formativa por dos (2) expertos en el área y sometidos a una rigurosa revisión. Asimismo es una revista indexada internacionalmente, por tanto se rige según estándares de calidad que son asumidos por la comunidad científica internacional.

En cuanto a los aspectos formales de presentación del texto, esta revista en línea señala lo siguiente: a) los resultados de revisiones documentales, informes de investigación en las modalidades cualitativa y cuantitativa, propuestas y experiencias educativas, deben tener una extensión entre 20 y 25 páginas. Para los ensayos, la extensión debe estar entre 12 y 15 páginas; y para las revisiones bibliográficas la extensión será entre 10 y 12 páginas; b) se utilizará para la transcripción del texto la letra Times New Roman, fuente 12 y el interlineado de espacio y medio; c) no se deben incluir en los trabajos apéndices, anexos o agradecimientos. No más de seis (6) ilustraciones (gráficos, cuadros, fotos o dibujos); d) se deben evitar las notas al pie de página. Sin embargo, si son necesarias, deberán ser incluidas al final del trabajo; e) el trabajo debe estar debidamente paginado, utilizando para ello el borde inferior izquierdo de cada página; f) el estilo de redacción, presentaciones, gráficos, citas y otros aspectos debe seguir las normas APA (American Psychological Association, 1994). 4ta Edición. Washington, DC: Autor. De igual modo se puede hacer referencia al Manual de Trabajos de Grado de Especialización y Maestría y Tesis Doctorales de la UPEL, Año 2007.

En líneas generales, los artículos de las revistas electrónicas tienden a presentar un esquema de escritura académica lineal, no obstante, la característica primordial de estas publicaciones es la brevedad en su extensión, lo que constituye un factor a favor de estas, ya que generalmente el internauta no dispone de mucho tiempo para leer. Además, "un texto largo podría contener más información, pero podría tomar demasiado tiempo leerlo, por lo que los usuarios abandonarán el sitio y buscarán piezas más cortas, más fáciles en otro lugar" (Nielsen citado en Franco, 2008, p. 63). Todo ello en atención a la economía de palabras, lo que finalmente ha venido a convertirse en pauta de todo texto escrito en Internet.

\section{La Escritura en un Medio Digital}

Un mundo altamente globalizado como el actual, se caracteriza por la inmediatez en 
la difusión de la información. Los acontecimientos en pleno desarrollo llegan a los usuarios a través de la Red a una velocidad pasmosa. Ya no hay que esperar al día siguiente para enterarse de lo que está sucediendo en los rincones más apartados del globo gracias a los periódicos digitales. Esto hace que dichos recursos suministrados por la Web cada día ganen más terreno entre quienes necesitan estar informados oportunamente y sin tiempos prolongados de espera.

Uno de los aspectos más relevantes en la difusión de la información a través de un medio digital lo constituye el dominio de la escritura para la Web, ya que esta significa en gran parte, regresar a dos de las bases del oficio periodístico: la buena redacción y la buena edición. El resto, definitivamente una menor proporción, está determinado por las particularidades de este nuevo medio, tal como lo manifiesta Franco (ob. cit.).

La escritura en un periódico digital toma como referente teórico la pirámide invertida propuesta y adaptada a los medios digitales del presente por el periodista Guillermo Franco (ob. cit.), como ruta para estructurar el texto escrito online. En este sentido, el mencionado autor, al citar a Nielsen, justifica su uso como de utilidad para los periódicos porque los lectores pueden parar en cualquier momento y conseguirán aún las partes más importantes del artículo.

Este formato se asocia con la invención del telégrafo, en 1837 y la preocupación de que la transmisión pudiera cortarse. Se trataba de entregar el mensaje lo antes posible. Sin embargo, agrega el autor antes citado, esta forma de estructurar el texto periodístico ha sido usada durante años por los periódicos, y puede ser adaptada al ambiente online con ajustes relativamente menores.

Según Mencher (citado en Franco, ob. cit.), la pirámide invertida ha persistido porque satisface las necesidades de los usuarios de los medios, quienes "desean saber qué pasa tan pronto la historia comienza a desenvolverse. Si es interesante, prestarán atención. De otra forma, se irán a otra parte. La gente está muy ocupada para detenerse sin ninguna recompensa" (Franco, ob. cit., p. 53).

La tradicional pirámide invertida además de ser recuperada por Internet, fue modernizada y se le otorgó un nuevo estilo que la hace fundamental al redactar noticias para la Web, solo que adaptada a nuevas exigencias, tales como palabras cortas, conocidas y precisas. Un ejemplo de ello es escribir fin en vez de propósito, porque es más corto; 
trabajo en vez de rol, porque es más conocido, y colibrí en vez de ave porque es más preciso (si de un colibrí se trata).

En cuanto a la frase, según las nuevas exigencias de la escritura para la Web, debe ser corta, sin excesos de incisos ni de circunstancias. El núcleo de cada frase, el verbo, debe ser fuerte y directo, por ejemplo: aclaró, y no débil y sinuoso como hizo la aclaración. Ello responde a la economía de las palabras de la escritura en Internet, lo cual se ha convertido en una pauta de todo texto escrito, que inevitablemente termina siendo una pauta para todos los medios. (Ávila citado en Franco, ob. cit.). Además, "hay que recordar que los textos muy extensos son adecuados para otros formatos pero no para la Web" (Auster, 2007, p. 1).

Una vez realizada la introducción anterior, a continuación se describe la estructura de la pirámide invertida y se identifican sus elementos constitutivos. En este punto es pertinente saber que utilizar la estructura de pirámide invertida significa comenzar el texto con la información más importante y después ir entregando más en orden decreciente de importancia.

Nielsen (citado en Franco, ob. cit.), lo explica de una forma ligeramente diferente:

Comience el artículo diciéndoles a los lectores la conclusión, siga con la más importante información de apoyo y termine dando contexto. Este estilo es conocido como pirámide invertida por la simple razón de que da la vuelta al estilo tradicional de pirámide (p. 51).

Es oportuno mencionar que este esquema de la pirámide invertida difiere completamente de la estructura de un artículo científico, en el cual las conclusiones son lo último que se menciona, luego de secciones tales como la introducción, los objetivos, la justificación, la metodología, entre otros. De manera análoga sucede con el fallo de una corte de justicia, donde la decisión se deja para la última página luego de los “considerandos". Es en estas últimas páginas -de las conclusiones en un artículo científico o las decisiones judiciales- donde el periodista capta el insumo básico para elaborar la versión periodística.

Por su parte, Mencher (citado en Franco, ob. cit.), señala los siguientes elementos que conforman la estructura de la pirámide invertida: la entrada o 'lead', el material que explica y amplía el 'lead', párrafos de contexto y material secundario o menos importante.

Es conveniente explicar que Lead es tomado de la palabra inglesa que significa 'liderar' o 'conducir': 'Es, por tanto, el párrafo inicial que 'conduce' tanto al periodista 
para desarrollar en seguida la información, como al lector en el conocimiento del hecho. Así se constituye en la puerta de entrada a la noticia" (Manual de Redacción del periódico 'El Tiempo', de Colombia citado en Franco, ob. cit., p. 51).

A continuación se presenta el esquema básico de la pirámide invertida utilizado en la redacción del texto periodístico. (Ver gráfico 1).

\section{Gráfico 1}

\section{Pirámide invertida, nivel básico de utilización.}

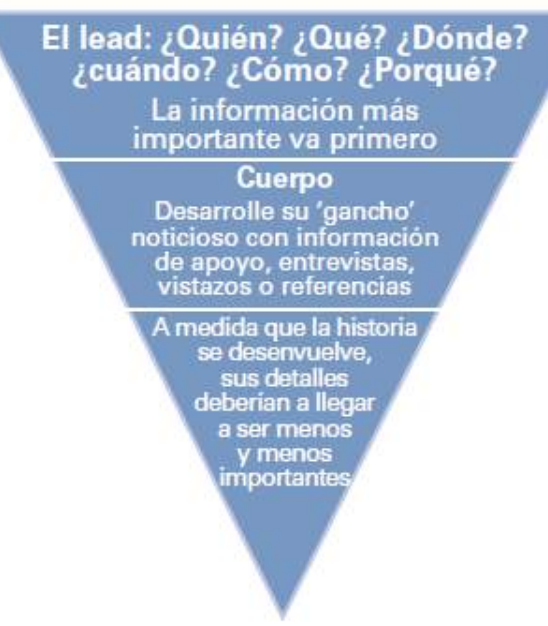

Fuente: Franco (2008). Cómo escribir para la web. Bases para la discusión y construcción de manuales de redacción 'online'. (p. 55).

\section{La Escritura en las Redes Sociales}

El ser humano se caracteriza por su naturaleza social, por la necesidad de relacionarse con sus congéneres a través de las diferentes formas de comunicación. Por ello el lenguaje humano, (oral y escrito) adquiere cada día mayor valor como sistema de comunicación y de representación del mundo. Esto ha sido así desde que el hombre comenzó a poblar la tierra hasta el presente.

Aunque la oralidad es la manera originaria en que se comunican los humanos, el texto escrito ha sido la primera forma de comunicación humana en fijarse en soportes más o menos duraderos. Al respecto, Cassany (2000), afirma que la invención de la escritura hace 3.000 años ensanchó las prestaciones del habla y supuso avances incuestionables en el devenir humano.

En ese devenir de la humanidad las formas de comunicación, tanto oral como escrita, 
han experimentado grandes cambios. Ya las personas no tienen la necesidad de acudir a las editoriales tradicionales a la hora de dar a conocer su producción escrita como un libro o un artículo, con las consabidas erogaciones pecuniarias. Basta con acceder a Internet, seleccionar alguna red social y publicar su trabajo.

En relación con las redes sociales, se pueden definir como estructuras compuestas por personas u otras entidades humanas las cuales están conectadas por una o varias relaciones que pueden ser de amistad, laboral, intercambios económicos o cualquier otro interés común.

Algunas de ellas, como scribd, slideshare, prezi, twitter, Facebook, YouTube, blogs, edmodo, entre otras, permiten diseminar recursos educativos abiertos (REA), entre los que pueden identificarse: "cursos completos, materiales de cursos, módulos, libros, artículos, video, exámenes, software y cualquier otra herramienta, material o técnica empleada para dar soporte al acceso del conocimiento" (Burgos, 2010, p. 1), "que se encuentran en el dominio público o que han sido publicados con una licencia de propiedad intelectual que permite su utilización, adaptación y distribución gratuitas" (UNESCO, 2002, p. 1).

Las redes sociales mencionadas han hecho posible que tanto escritores noveles como experimentados, puedan dar a conocer su producción escrita de manera abierta. Estas permiten compartir objetos digitales, la creación de comunidades de una misma clase, compartir intereses comunes de una asignatura, facilitar la colaboración entre los miembros, la utilización del tablón de anuncios, publicar comentarios de todos los integrantes en torno a un tema determinado, entre otras actividades.

Una de las más utilizadas en la actualidad es Facebook, un sitio Web gratuito de redes sociales creado por Mark Zuckerberg en 2004, que originalmente era un sitio para estudiantes de la Universidad Harvard, pero actualmente está abierto a cualquier persona que tenga una cuenta de correo electrónico. Esta red social funciona como una plataforma en la que se gestionan conversaciones y se establecen relaciones personales a través de la escritura, "prácticas discursivas que están determinadas por las relaciones afectivas o de confianza que se tejen en la red" (Gallego, 2014, p. 14).

Según Moreno (2015), esta red social que alcanzó en julio de 2015 la cantidad de 1.490 millones de usuarios activos en el mundo, se ha popularizado en los últimos años, sobre todo en la población joven con edades comprendidas entre los 15 y 24 años, periodo 
en el que se encuentran los estudiantes de educación media y superior. En consecuencia, este hecho convierte a Facebook en una herramienta valiosa desde el punto de vista educativo, pues puede ser utilizado por el docente para estimular el aprendizaje colaborativo entre sus estudiantes, aprovechando los conocimientos previos de estos jóvenes que, en muchos casos, superan a los del docente.

De acuerdo con lo que señala Valderrama (2013), en este espacio los jóvenes encuentran una manera de formular preguntas académicas y conseguir respuestas de otros compañeros de clases más aventajados, esto se debe a que el adolescente busca el apoyo o la guía de personas afines que le inspiren confianza, y en esta etapa "las personas con quien más próximo se siente son los amigos" (p. 45). Esto tiene que ver con lo que Vygotsky (1998) denominó zona de desarrollo próximo (ZDP), definida como:

...la distancia entre el nivel real de desarrollo, determinada por la capacidad de resolver independientemente un problema, y el nivel de desarrollo potencial, determinado a través de la resolución de un problema bajo la guía de un adulto o en colaboración con otro compañero más capaz (p. 133).

Lo mencionado, refleja que la interacción social con los otros (especialmente los que saben más: expertos, maestros, padres, niños mayores, iguales, etc.) tiene importancia fundamental para el desarrollo psicológico (cognitivo, afectivo, entre otros.) del niño/estudiante. Además de las relaciones sociales, la mediación a través de instrumentos (físicos y psicológicos como: lenguaje, escritura, libros, computadoras, manuales) permiten el desarrollo del estudiante.

Sin embargo, el uso extendido de Facebook ha creado una gran polémica entre sus defensores y detractores, en relación con lo benéfico o lo dañino que puede resultar en términos educacionales, pues al no tener un regulador de la información que por allí circula, tampoco estándares que midan la calidad de un texto en cuanto a ortografía, coherencia y/o veracidad, su credibilidad y valor pedagógico es cuestionable.

No obstante lo señalado en los párrafos precedentes, es indudable que con la llegada de Facebook se han adoptado nuevas prácticas comunicativas, sobre todo en la escrita, lo que podría conllevar una modificación de su esquema de reglas gramaticales y ortográficas, e incluso crear nuevas, esto en atención al uso y costumbre de algunos elementos lingüísticos utilizados en la mencionada red social. Esta situación se ve materializada en la reciente inclusión de términos relacionados con la cultura digital en el Diccionario de la 
Real Academia Española (2015), como por ejemplo la palabra chat definida como: (Del ingl. chat; propiamente 'charla'). 1. m. Inform. Intercambio de mensajes electrónicos a través de internet que permite establecer una conversación entre dos o varias personas. 2. m. Inform. Servicio que permite mantener conversaciones mediante chats. Igualmente sucede con el término web cuyo significado es: (Del ingl. web, red, malla). 1. f. Inform. Red informática. V. página web.

Una de las modificaciones en el lenguaje escrito que han traído las redes sociales, particularmente Facebook, tiene que ver con la eliminación de letras y la sustitución por otras cuyos nombres o fonemas cubren la ausencia de las correspondientes. Esta técnica tiene como propósito economizar la cantidad de caracteres al momento de interpretar los mensajes, por ejemplo: no lo c en lugar de no lo sé; ksa en lugar de casa; enamora2 por enamorados; klac en lugar de clase, entre otros. También se acostumbra usar smileys y emotes, conocidos como emoticones en español, que son signos para comunicar emociones mediante expresiones del rostro, por ejemplo: $=)$ (carita sonriente $),=($ (carita de llanto $)$.

Si bien esta modificación de códigos escritos ha despertado alarma entre algunos especialista de la lengua, otros creen que esto se debe a que "La Web es un nuevo medio lingüístico, mucho más dinámico que la escritura tradicional" (Crystal citado en Valderrama, ob. cit., p. 49). Esto quedó evidenciado por Valderrama (ob. cit.) en un estudio realizado, en el que pudo confirmar que el $90 \%$ de la muestra seleccionada escribe en las redes sociales de manera diferente que cuando lo hacen para la academia, incluso algunos de ellos manifestaron sentirse libres cuando escriben en estos medios digitales sin la preocupación de seguir reglas gramaticales.

Los resultados anteriores coinciden con los obtenidos en otro estudio realizado por Cornejo (2013), en el que dicho autor encontró que los estudiantes que conformaron su muestra se sintieron mejor en las actividades que hacían en Facebook, que en las que hacen en el aula de clase con el cuaderno, el diccionario y los libros. Agregaron, que se sienten más activos cuando están frente al computador viendo un video y escribiendo sobre éste o leyendo una historia y luego comentándola y leyendo si algún compañero opinó lo mismo que ellos, cosa que según los mismos, no se puede hacer en el aula porque se ocasiona indisciplina.

Lo señalado tiene que ver con el uso de la escritura espontánea, que según Cornejo (ob. cit.), es una de las características principales que tiene Facebook para que los usuarios puedan interactuar con las demás personas, tanto en el intercambio de información como para compartir recursos propios o bajados de internet. 
En atención a las experiencias señaladas previamente, se puede decir que Facebook es un recurso fácilmente aprovechable como un aula virtual, ya que por su versatilidad, permite diseminar documentos en diferentes formatos: Word, pdf, presentaciones en power point, así como compartir enlaces a otros sitios Web especializados. Puede además ser utilizado como una herramienta que facilita el trabajo colaborativo, que fomenta el diálogo y la responsabilidad mutua, que ayuda a desarrollar habilidades de lectura y de escritura, siempre y cuando el docente oriente su uso de manera pedagógica (Piscetelli citado en Cornejo, ob. cit.).

Visto de esa manera, Facebook compromete al docente a estimular la producción escrita con apego a los patrones lingüísticos como corresponde en un escenario educativo virtual y, por otra parte, a fomentar el buen uso de las redes sociales, de tal manera de convertirlas en aliadas en la construcción del conocimiento de una forma interactiva y creativa.

Otras de las redes sociales que ha venido ganando auge entre miles de usuarios es Twitter, un sitio microblogging con millones de cuentas y seguidores, utilizado por ciudadanos comunes y corrientes, pero también por instituciones estatales, medios de comunicación, escritores y miembros de las más diversas organizaciones, desde partidos políticos, clubes deportivos y fanáticos de todo tipo, hasta presidentes de varias naciones.

Esta red social ha revolucionado la forma de escribir; ahora hay que hacerlo utilizando todas las teclas, jugar con la imaginación y tuitear combinando letras, símbolos, imágenes, iconos, emoticonos, esto es lo que el periodista español Mario Tascón ha denominado la Twittergrafía. Esto se debe a que los mensajes en estos microbloggings se ven reducidos a 140 caracteres, lo que convierte la escritura de un tuit en un reto sintáctico. Este ha devuelto un interés renovado en la gramática, según Vargas (2013). Este es uno de los mejores ejercicios de estilo que se conoce, según opinión de Ferreyra (2012).

En relación con el uso de Twitter en educación, López (2012) enumera una lista de posibles aplicaciones en los procesos educativos, entre las cuales señala:

- Los docentes de Lenguas Extranjeras pueden solicitar a sus estudiantes publicar al menos cinco mensajes semanales en el idioma que estén aprendiendo. Cada semana, en la clase, se presenta a todo el grupo los mensajes con más fallas, de manera que aprendan de sus propios errores y de los de otros compañeros. 
- Promover en los estudiantes el desarrollo de habilidades de selección y síntesis de información de manera que expresen una idea completa en solo 140 caracteres. Para esto resulta muy apropiado introducir a los estudiantes en formas de escritura breves como los versos tradicionales japoneses conocidos como "Haiku" y la poesía de creación colectiva "Renga".

- Plantear a los estudiantes un tema o problema, días antes de la clase, para que éstos realicen una lluvia de ideas por medio de Twitter. Así, en la clase se dispondrá de más tiempo para analizar el tema o para aplicar conocimientos.

Algunas de las aplicaciones antes mencionadas coinciden con las propuestas por Wheeler (2009) como por ejemplo: Hacer resúmenes de un texto, capítulo, entre otros. Límite 140 caracteres; micro escritura- escritura progresiva y colaborativa para crear microrrelatos; y Lingua Tweeta- para el aprendizaje de idiomas modernos.

Como se puede apreciar, son diversas las aplicaciones que presenta Twitter en el proceso de producción escrita en educación. Sin embargo, el docente con su creatividad puede proponer otras aplicaciones de este microblogging de 140 caracteres.

No obstante el crecimiento indiscutible de Twitter y el interés generado en la población mundial, esta manera de escribir en dicha red social ha sido criticada por muchos, quienes concuerdan en que la twittergrafía y en general las abreviaturas que se utilizan en las redes sociales que surgieron para ahorrar espacios, terminaron masificándose. Añaden además, que esta se ha arraigado tanto en los estudiantes que no es extraño que la utilicen incluso en las pruebas.

Según Carr (citado en Celis, 2011), el bombardeo constante de micromensajes provenientes de las redes sociales como Facebook y Twitter, producen una distracción enorme cuando se deben realizar multitareas digitales inherentes a las nuevas tecnologías.

Agrega el antes citado autor, que:

La multitarea, instigada por el uso de Internet, nos aleja de formas de pensamiento que requieren reflexión y contemplación, nos convierte en seres más eficientes procesando información pero menos capaces para profundizar en esa información y al hacerlo no solo nos deshumanizan un poco sino que nos uniformizan (p. 1).

Lo expresado por Carr (citado en Celis, ob.cit.) coincide con la opinión de Rivero 
(citado en Arroyo, 2013), quien afirma que hay un cambio del lenguaje en general que partió con Messenger, siguió con Whatsapp y Twitter que limita sus mensajes a 140 caracteres. Además, reconoce que hay una pérdida en la calidad del lenguaje, traducido en una menor capacidad de redacción y una pésima ortografía.

Pese a todas las opiniones desfavorables acerca de la escritura en las redes sociales, particularmente en Twitter, otros especialistas en materia comunicacional son más conservadores al respecto. Tal es el caso de Rodríguez (citado en Arroyo, ob. cit.), quien está convencido de que es perfectamente posible crear textos poéticos breves de valor literario y difundirlos entre sus seguidores de Twitter. Este estilo de escritura es conocido como Twitteratura, que además cuenta desde hace ya tres años, con el respaldo del Instituto de Twitteratura Comparada de Francia, organizador del Festival Internacional de "Twitteratura" (Arroyo, ob. cit.).

Como se ha podido observar, son diversas las opiniones que se tejen en torno a Facebook y Twitter, y la forma en que estas redes sociales han cambiado la manera de comunicarse en el presente siglo, con énfasis en la modalidad escrita, sobre todo en el ámbito académico. En este sentido, se dice que estas han llevado a la escritura a enfrentar un cambio que la podría condicionar a modificar sus reglas gramaticales y ortográficas e incluso a crear nuevas, y poner de manifiesto el estado de transición en que se encuentra el código escrito en las redes (Valderrama, 2013).

Como resultado de lo anterior, han surgido muchas voces que de alguna manera tratan de satanizar dichas herramientas web, mientras que otras más benévolas, se esfuerzan por demostrar sus bondades. Lo cierto es que tanto los profesionales, como gente de negocios, amas de casa, estudiantes, escritores expertos y noveles actualmente poseen una cuenta en alguna de estas redes, o bien en ambas. Lo importante es que al parecer, éstas llegaron para quedarse.

\section{A MANERA DE CONCLUSIÓN ¿POR QUÉ LA ESCRITURA DIGITAL?}

Las tecnologías de la información y la comunicación (TIC) han reivindicado el valor de la escritura. Se escriben mensajes de texto (SMS) a través de celulares, correos electrónicos por Internet, notas sociales en Facebook, noticias en Twitter. Se completan formularios electrónicos en sitios Web de entidades bancarias, los estudiantes formalizan 
sus inscripciones en los portales de las universidades y los docentes transcriben calificaciones. Cualquier persona medianamente alfabetizada para el mundo digital puede pagar ciertos servicios, comprar un libro o un electrodoméstico, entre otras aplicaciones propias de los medios digitales. Al respecto, Cassany (2004) afirma:

Nos guste o no, una parte muy importante de la comunicación escrita, tradicionalmente desarrollada en entornos analógicos o con objetos físicos (papel, libro, lápiz, correo postal) compuestos por átomos, hoy está emigrando de modo acelerado hacia entornos digitales (ED) o electrónicos (ordenador, red, pantalla), que representan y transmiten la información por dígitos) (p. 1).

No obstante lo mencionado anteriormente, es innegable que la escritura análoga mantiene vigencia en muchos casos, en los cuales se hace imprescindible dejar un testimonio en físico de alguna documentación legal como por ejemplo un título profesional, una sentencia judicial, una partida de nacimiento, entre otros. "Quizá nunca desaparezcan determinados documentos como certificados, testamentos o contratos con firmas manuscritas, porque ofrecen prestaciones irremplazables" (Cassany, 2000, p. 2). Se trata más bien de una coexistencia, "implica que debemos acostumbrarnos a que la palabra escrita viene empacada en dos estuches distintos, mas no contrapuestos..." (Barrera citado en Espinoza y Morales, 2002, p. 20).

Sin embargo, para efectos del objetivo de este artículo es perentorio precisar la importancia de los textos digitales. A tal fin se presenta un gráfico en el cual se resumen las características más destacadas de la escritura digital y que han sido ampliamente desarrolladas en el presente trabajo. (Ver gráfico 2). 


\section{Gráfico 2}

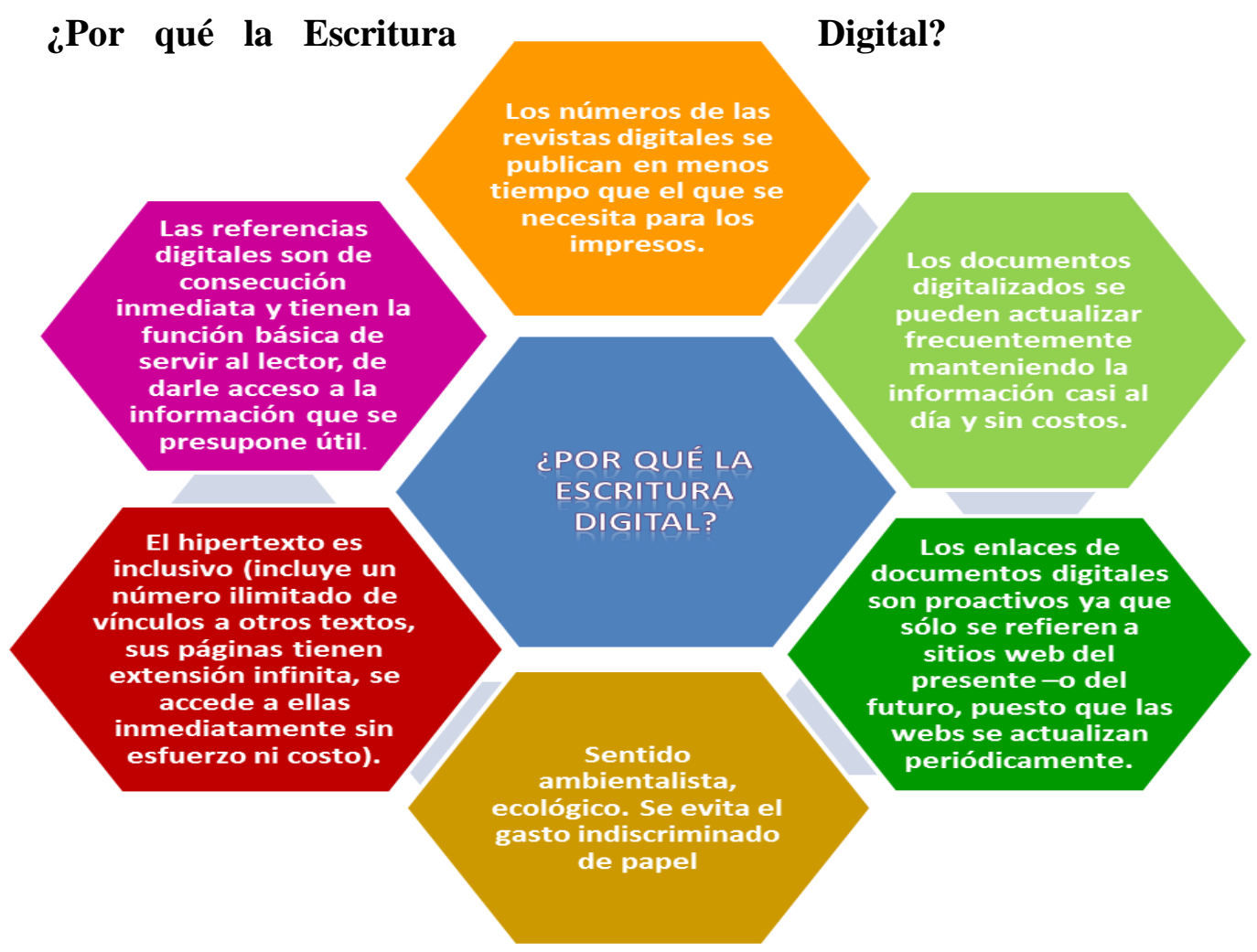

Fuente: Elaboración propia del autor con base en la revisión documental.

Por todo lo mencionado anteriormente, se puede afirmar que los textos digitales han venido permeando el quehacer diario, razón por la cual es imperativo para las personas familiarizarse con esta forma de comunicación, en la que los medios físicos como el papel y el lápiz cada vez más están cediendo espacios al teclado y a las pantallas de los ordenadores personales. Al respecto, Borda (citado en Morales y Espinoza, 2003) señala que para Microsoft "en el año 2020, 50\% de todo lo que leamos tendrá formato electrónico" (p. 219).

Sin embargo, el usuario de la Red debe establecer unos patrones de búsqueda que le garanticen que los documentos electrónicos descargados cuenten con el aval de instituciones de reconocida calidad académica, ya que existen numerosos sitios Web de dudosa reputación e incuestionable mediocridad, cuyos artículos adolecen de ciertas irregularidades, como por ejemplo: no cuentan con el arbitraje de expertos, se desconoce su autoría, así como la institución que respalda dicha publicación, presentan poca profundidad en el contenido y deficiente calidad en el discurso escrito, entre otros. 
En atención a lo señalado en el párrafo anterior, en este punto del presente artículo es apropiado señalar algunas de las implicaciones que conlleva el texto digital, y que se presentan en el gráfico 3. Este aparece encabezado por la alfabetización digital, una de las principales limitaciones de muchos usuarios de la Red, detrás de la cual se esconden más que algunas destrezas para manejar ordenadores e Internet. Se trata de las competencias básicas para leer y escribir un texto multimedia. "Es la capacidad de comprender y utilizar la información de fuentes diversas y múltiples formatos, cuando se presenta a través del ordenador" (Giister citado en Gutiérrez Martín, 2003, p. 4). (Ver gráfico 3).

\section{Gráfico3}

\section{Implicaciones de la Escritura Digital}

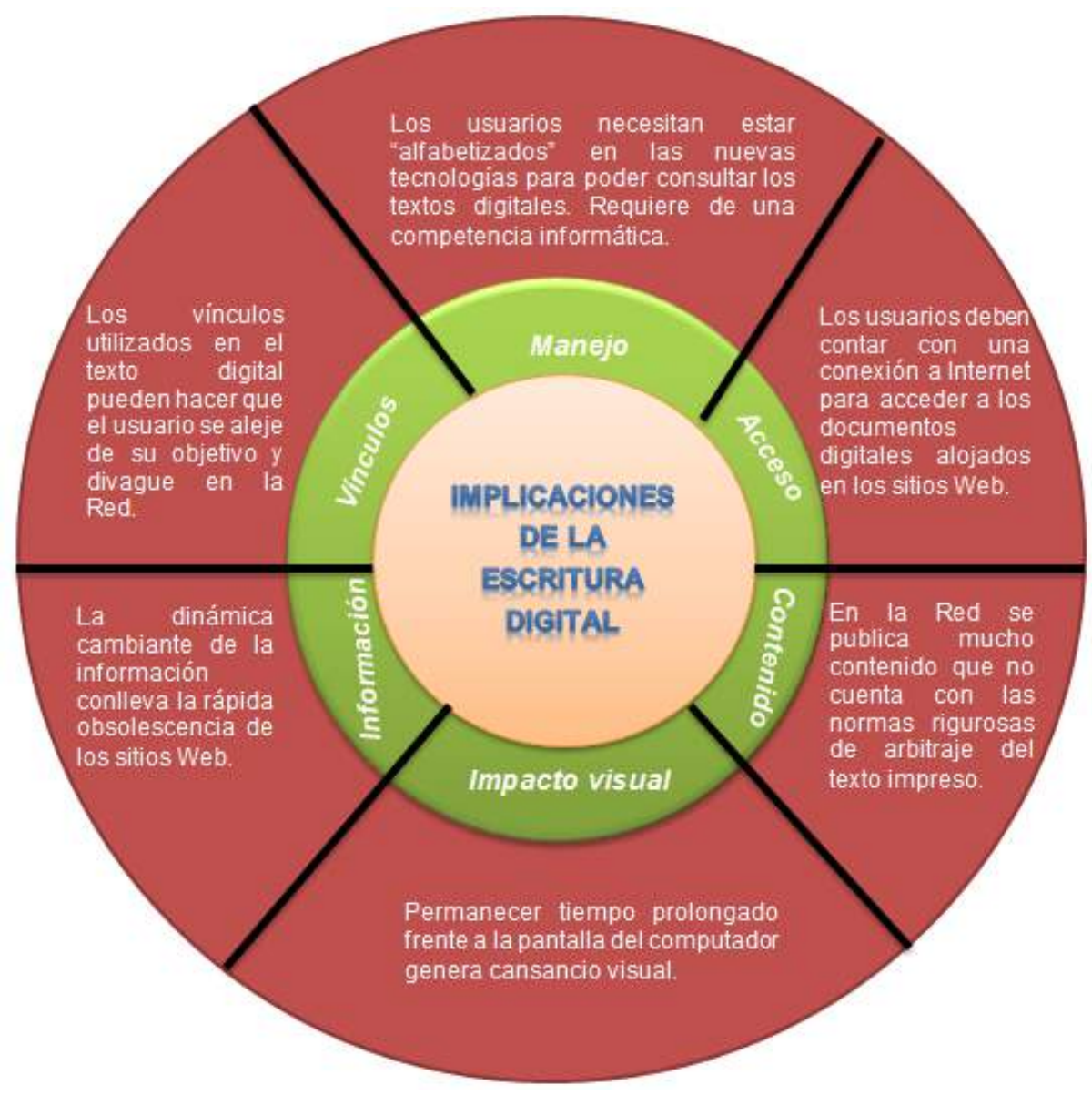

Fuente: Elaboración propia del autor con base en la revisión documental. 
Para recapitular el tema de los sitios Web de dudosa reputación, se debe aclarar que si bien es cierto que estos existen, no es menos cierto que también coexisten entornos digitales de reconocida trayectoria académica cuyos textos son ampliamente recomendados. Tal es el caso del repositorio saber.ula.ve, perteneciente a la Universidad de Los Andes, en el que se gestiona, difunde, y facilita el acceso a documentos electrónicos a texto completo creados por la comunidad universitaria.

Así mismo, hay revistas indizadas de reconocida trayectoria en el mundo académico como Educere, avalada por Redalyc.org, Red de Revistas Científicas de América Latina, el Caribe, España y Portugal cuyos artículos son rigurosamente arbitrados, al igual que la revista Scielo (Scientific Electronic Library Online).

Para culminar, se puede afirmar que los entornos digitales (ED) invitan a escribir como nunca antes ningún otro soporte cultural había hecho, lo cual requiere activar unas estrategias de escritura nuevas por parte del docente del siglo XXI, así como a familiarizarse con los nuevos soportes de la escritura digital, puesto que esta empieza a ser ya tan importante como la analógica, de allí la necesidad de vincular las TIC al proceso educativo.

Además, es un hecho que la era digital está aquí y nos toca directa o indirectamente a todos. Así mismo, contribuye a la formación del desarrollo de habilidades críticas en el estudiante que permiten tomar posición frente a la cantidad de información que brindan las TIC y contribuye al fortalecimiento de los procesos comunicativos. (Calle, 2014, p. 28).

\section{REFERENCIAS}

Arroyo, M. (2013). Redes sociales. El nacimiento de una nueva escritura. Sala de Prensa Universidad de Talca. [Página Web en línea]. Disponible: http://www.utalca.cl/link.cgi/SalaPrensa/RSU/6626. [Consulta: 2015, Enero 13].

Auster, E. (2007). Tips sobre escritura web. Maestros del Eb. [Página Web en línea]. Disponible: http://www.maestrosdelweb.com/tips-sobre-escritura-web/. [Consulta: 2015, Enero 8].

Bisquerra, R. (1989). Métodos de investigación educativa. Barcelona, España: Ediciones CEAC.

Buendía, L., Colás, P., y Hernández, F. (1998). Métodos de investigación en psicopedagogía. Madrid: McGraw-Hill / Interamericana de España.

Burgos, J. (2010). Rúbricas para evaluar Recursos Educativos Abiertos (REA). 
[Documento en línea], Disponible: http://www.temoa.info/es/rubrica. [Consulta: 2015, Enero 6].

Calle A. Gerzon (2014). Las habilidades del pensamiento crítico durante la escritura digital en un ambiente de aprendizaje apoyado por herramientas de la web 2.0. [Revista en línea] Universidad Autónoma del Caribe, 12 (1), 27-45. Disponible: http://www.scielo.org.co/pdf/encu/v12n1/v12n1a03.pdf. [Consulta: 2016, Marzo 01].

Cassany, D. (2000). De lo analógico a lo digital. El futuro de la enseñanza de la composición. [Documento en línea], Disponible: http://www.lecturayvida.fahce.unlp.edu.ar/numeros/a21n4/21_04_Cassany.pdf.

Cassany, D. (2004). La alfabetización digital, en Víctor M. Sánchez Corrales ed. Actas. XIII Congreso Internacional de ALFAL. San José de Costa Rica: Universidad de Costa Rica, 2004; p. 3-20. ISBN: 9977-15-120-2.

Celis, B. (2011). Un mundo distraído. El País. [Página Web en línea]. Disponible: http://elpais.com/diario/2011/01/29/babelia/1296263535_850215.html. [Consulta: 2015, Enero 13].

Chartier, R. (2010). Aprender a leer, leer para aprender, Nuevo Mundo Mundos Nuevos [Documento en línea], Disponible: http://nuevomundo.revues.org/58621. [Consulta: 2015, Enero 4].

Cornejo, E. (2013). El desarrollo de las competencias cognitivas básicas en estudiantes de sexto grado a través del uso del Facebook como herramienta mediadora del proceso de aprendizaje. [Documento en línea], Disponible: http://www.eumed.net/librosgratis/2014/1375/. [Consulta: 2015, Enero 9].

Dávila, A., Ruiz, C., y Francisco, J. (2013). Modelo tecno-pedagógico para la implantación de la modalidad semipresencial en la educación universitaria. Revista Educare. [Revista en línea], $3 . \quad$ Disponible: http://revistas.upel.edu.ve/index.php/educare/issue/view/91.

Day, R. (2005). Cómo escribir y publicar trabajos científicos. [Libro en línea]. 3a. ed. Washington, D.C.: OPS, () 2005. (Publicación Científica y Técnica No. 598). Disponible: http://www.bvs.hn/Honduras/pdf/Comoescribirypublicar.pdf.

Díaz, A. (1999). Aproximación al texto escrito. Medellín: Universidad de Antioquia.

Díaz, J. (2000). La escritura digital. Talaia. [Documento en línea], Disponible: https://www.uv.es/lejarza/amv/adefini/pdf/escridig.pdf. [Consulta: 2015, Enero 1].

Espinoza, N. y Morales, O. (2002). El texto electrónico: ¿la desaparición de lo impreso o la aparición de una nueva fuente de lectura? [Revista en línea]. Disponible: http://webdelprofesor.ula.ve/odontologia/oscarula/publicaciones/articulo21.pdf. 
Ferreyra, A. (2012). Mario Tascón y la Twittergrafía en la sección columnistas. Crónica Z. [Página Web en línea]. Disponible: http://cronicaz.com.ar/2011/10/12/mario-tascon-yla-twittergrafia-en-la-seccion-columnistas/. [Consulta: 2015, Enero 12].

Franco, G. (2008). Cómo escribir para la web. Bases para la discusión y construcción de manuales de redacción 'online'. [Libro en línea], Disponible: https://knightcenter.utexas.edu/Como escribir para la WEB.pdf. [Consulta: 2015, Enero 12].

Gallego, G. (2014). Concepciones y sentidos de la escritura en Facebook. Visión de estudiantes y docentes de la institución educativa Escuela Normal de Jericó. [Documento en línea], Disponible: http://ayura.udea.edu.co:8080/jspui/bitstream/123456789/376/1/PA0758.pdf.

[Consulta: 2015, Enero 9].

Gutiérrez Martín, A. (2003). Alfabetización digital Algo más que botones y teclas. [Libro en línea], Disponible: http://www.terras.edu.ar/biblioteca/2/2GUTIERREZ-MARTINAlfonso-CAP5-La-alfabetizacion-a-la-era-de-Internet.pdf. [Consulta: 2015, Marzo 1].

López, J. (2012). Usos de Twitter en educación. [Documento en línea]. Disponible: http://www.eduteka.org/TwitterEducacion.php. [Consulta: 2015, Enero 12].

Morales, O. y Espinoza, N. (2003). Lectura y escritura: convivencia entre lo impreso y lo electrónico. [Revista en línea], 22. Disponible: http://www.saber.ula.ve/bitstream/123456789/19786/1/articulo10.pdf. [Consulta: 2016, Febrero 24.

Moreno, M. (2015). Facebook ya tiene 1.490 millones de usuarios activos. [Página Web en línea]. Disponible: http://www.trecebits.com/2015/07/30/facebook-ya-tiene-1-490millones-de-usuarios-activos/.

Organización de las Naciones Unidas para la Educación, la Ciencia y la Cultura Unesco (2002). Recursos Educativos Abiertos. [Documento en línea], Disponible: http://www.unesco.org/new/es/communication-and-information/access-toknowledge/open-educational-resources/. [Consulta: 2015, Enero 6].

Real Academia de la Lengua Española. (2015). Diccionario de la lengua española. [Página Web en línea]. Disponible: http://www.rae.es/recursos/diccionarios/drae. [Consulta: 2015, febrero 20].

Revista Educare (2015). [Página Web en línea]. Disponible: http://revistas.upel.edu.ve/index.php/educare. [Consulta: 2015, Enero 4].

Valderrama, R. (2013). De la escritura en Facebook a la escritura académica. [Documento en línea]. Disponible: https://es.scribd.com/doc/203347651/De-la-escritura-enFacebook-a-la-escritura-adacemica. [Consulta: 2015, Enero 14]. 


\section{LA ESCRITURA EN LOS ENTORNOS DIGITALES}

Mario Boza ( pp. 153-176)

Vargas, F. (2013). La sintaxis y el tuit perfecto. [Documento en línea], Disponible: http://cronicaz.com.ar/2013/08/20/la-sintaxis-y-el-tuit-perfecto/.

Vygotsky, L. (1988). El desarrollo de los procesos psicológicos superiores. México: Editorial Crítica, Grupo editorial Grijalbo.

Wheeler, S. (2009). Teaching with Twitter. [Documento en línea]. Disponible: http://stevewheeler.blogspot.com/2009/01/teaching-with-twitter.html. [Consulta: 2015, Enero 12]. 